\title{
Impacto da desoneração da contribuição previdenciária sobre a folha de pagamento de empresas do setor de construção civil: uma abordagem prática
}

\author{
Angelina Raissa da Silva Finizola \\ Centro Universitário de João Pessoa (UNIPÊ) \\ Vera Lucia Cruz \\ Universidade Potiguar (UnP) \\ Ramon Rodrigues dos Santos \\ Universidade Federal da Paraíba (UFPB)
}

Data da submissão: 10/08/2017

Data de aceite: 20/02/2019

\section{RESUMO}

O objetivo deste estudo foi apresentar e analisar os impactos causados pela implantação da desoneração da folha de pagamento em uma empresa do setor de construção em João PessoaPB. A metodologia aplicada para atingir o objetivo traçado pela pesquisa, se desenvolveu através de um estudo qualitativo, de cunho descritivo, baseado nas constantes alterações da legislação que instituiu a desoneração. $O$ período base para realização da pesquisa foi o primeiro trimestre de 2015. Com base nas análises dos dados, concluiu-se que, através da desoneração da folha de pagamento, a empresa analisada teve redução de $45 \%$ no valor recolhido à Previdência Social, o que significa que ela teve vantagem com a nova sistemática criada pelo governo federal.

\begin{abstract}
The present work addressed the changes that occurred after the entry into force of the legislation known as the "exemption from payroll" (Law $\mathrm{n}^{\circ} 12.546 / 2011$ ), which aims to reduce the tax burden levied on the payroll of the companies. Thus, the aim of this study was to present and analyze the impacts caused by the deployment of the exemption payroll in a company in the construction sector in João Pessoa-PB. The methodology applied to achieve the objective outlined by research, developed through a qualitative study, with a descriptive slant, based on the constant changes of the legislation that established the tax exemption. The base period for conducting the survey was the first quarter of 2015. Based on the analysis of the data, it was concluded that, through the tax exemption of the payroll, the company analyzed had a reduction of $45 \%$ on the collected amount to the Social security system, which means that she had the advantage with the new systematic created by the federal government.
\end{abstract}

Keywords: Payroll. Tax burden. Social security contribution. 


\section{INTRODUÇÃO}

Comparadas a outros países desenvolvidos acercas das práticas de políticas públicas, o Brasil demonstra em si, um cenário econômico com algumas limitações, que, podem esta restringindo seu desenvolvimento. Apontada como uma das causas da desaceleração econômica, "o desiquilíbrio da carga tributária", acabou ajudando a despertar o governo brasileiro, sobre a necessidade de criar novas políticas que pudessem alavancar a economia no país.

Com intuito de estimular a competitividade entre as empresas no Brasil e adequação das mesmas nos mercados internos e externos, o governo criou um plano com objetivo de promover a eliminação da contribuição previdenciária sobre a folha de pagamento das empresas de alguns setores, mudando a forma de incidência, antes era sobre a folha de pagamento e com a aplicação da Lei, passou a recolher um percentual sobre a receita bruta.

Em primeiro lugar, o governo está eliminando a atual contribuição previdenciária sobre a folha e adotando uma nova contribuição previdenciária sobre a receita bruta das empresas (descontando as receitas de exportação), em consonância com o disposto nas diretrizes da Constituição Federal. Em segundo lugar, essa mudança de base da contribuição também contempla uma redução da carga tributária dos setores beneficiados, porque a alíquota sobre a receita bruta foi fixada em um patamar inferior àquela alíquota que manteria inalterada a arrecadação - a chamada alíquota neutra. (GOVERNO FEDERAL, 2012 P. 01).

Nesse contexto, a desoneração da folha de pagamento foi adotada a partir da IN 1436/2013, a mesma foi criada com intuito de beneficiar algumas empresas de atividades especificas, através do cálculo da contribuição patronal, na qual, o cálculo da contribuição terá como base o faturamento mensal e, não mais da folha dos salários de seus funcionários.

Com essa alteração, as empresas da construção civil passaram a recolherem, a partir de $1^{\circ}$ de abril de 2013, $2 \%$ sobre a receita bruta em substituição ao porcentual de $20 \%$ a título de contribuição previdenciária sobre a folha de pagamento.

De acordo com a folha de São Paulo, 2016, os setores atendidos pela desoneração deixaram de pagar $20 \%$ de Contribuição Previdenciária, promoveeam uma redução do benefício, que custou aos cofres públicos R \$ 21,6 bilhões em 2014.

Com intuito de minimizar a situação, o governo atribuiu mudanças a partir de $1^{\circ}$ de junho de 2015, as empresas sujeitas à desoneração da folha de pagamento, ou seja, as empresas que recolhem suas contribuições previdenciárias sobre a receita bruta ("CPRB"), passarão a contribuir com alíquotas (sobre a receita bruta) de 2,5\%, em substituição à alíquota de $1 \%$ para as indústrias, e de 4,5\% para os demais segmentos, como, por exemplo, de informática, call Center e construção civil, em substituição à alíquota de $2 \%$. 
Dessa forma, as mudanças de alíquota, requer uma análise que possa levantar pontos necessários para discutir o andamento dessa adesão por parte das empresas, que mudou sua base de incidência de contribuição previdenciária, que antes era sobre a folha, e, a nova base de incidência, a receita bruta das empresas.

Em virtude da necessidade de criação de Leis que consigam ajustar a situação da carga tributária das empresas, os governos brasileiros gradualmente propõe incentivos para estimular a produção dentro do seu próprio país (estimular a competitividade das empresas) e expandir o comércio exterior, sendo assim, em 2011 o governo criou o Plano Brasil Maior, instituindo medidas para alcançar estes objetivos.

Dentre as principais medidas lançadas pelo plano, uma delas foi a desoneração da folha de pagamento, que consiste em substituir a contribuição previdenciária patronal (CPP) sobre a folha de pagamento, pela contribuição previdenciária sobre a receita bruta (CPRB). Em 2011, o plano iniciou com as empresas do ramo de Indústria de Couro e Calçados, as empresas de Tecnologia da Informação (TI) e Call Center. Em abril de 2012 foi lançada uma lista com 11 setores; em setembro de 2012 foram incluídos mais 25 setores, e em 2013 abrangeu os setores da Construção Civil e Comércio Varejista.

A estabilidade e o crescimento da economia, conjugados com o aumento da distribuição de renda, são verificados de maneira exemplar no âmbito das empresas de construção civil, [...]O setor de construção civil é o segmento que tem menor participação na carga tributária do Brasil. Isso se deve a algumas legislações fiscais do país que lhe dão vantagem competitiva em relação a outros ramos de atividade. (ALENCAR; LIMA, 2014).

Entretanto, indiferente aos demais setores, se houver uma demasiada carga tributária, poderá atrapalhar no que diz a respeito à avanços tecnológicos, a especialização de mão de obra (por não haver mão de Obra qualificada, poderá culminar um índice alarmante de desemprego no setor de construção civil).

A construção civil sofre forte transformação nos últimos anos com a disponibilidade de crédito, incentivos fiscais e legais, o que vem proporcionando um crescimento das empresas e do mercado de construção, no qual se pode destacar o subsetor de edificações, e neste o setor imobiliário (MELLO; AMORIM, 2009).

Diante do exposto formula-se o seguinte questionamento: Qual impacto que a desoneração trouxe a uma construtora na Paraíba? O objetivo geral deste trabalho foi apresentar os impactos causados pela implantação da desoneração da folha de pagamento no setor de construção. Em vista do objetivo geral, buscou-se identificar qual o impacto financeiro gerado com essa mudança desta construtora, avaliando diferenças entre a forma de 
tributação antes e depois da desoneração e evidenciando os benefícios implantados pela desoneração.

Com o intuito de incentivar a empregabilidade no país, o governo criou o Plano Brasil Maior, que contempla a Lei $\mathrm{n}^{\mathrm{o}} 12.546 / 2011$, com objetivo de sustentar o crescimento econômico e sua inserção na economia mundial. A pertinência do presente trabalho está no fato de que esta nova regra pode ser a saída para a redução da carga tributária sobre os salários e por consequência atingir seu objetivo de aumentar o número de empregados celetistas. Segundo Goulart (2011, p.14)

A estrutura tributária do Brasil é muito complexa e esse modelo implica em altos custos burocráticos para as empresas apurarem e pagarem seus impostos. Sabe-se também que boa parte desses tributos está ligada aos encargos trabalhistas, onde se incide as maiores alíquotas nacionais.

Outra alteração com a estipulação da Lei 12.546/11, foi a inclusão da Contribuição Previdenciária sobre a Receita Bruta na EFD-Contribuições. A EFD (Escrituração Fiscal Digital) é um arquivo instituído no Sistema Público de Escrituração Digital - SPED utilizado pelas pessoas jurídicas de direito privado que deve ser validado, assinado digitalmente e transmitido, via internet, ao ambiente SPED.

Dessa forma, o estudo se justifica como instrumento que apresenta a mudança de base de cálculo da contribuição previdenciária das empresas. Assim, foi possível identificar, as modificações causadas na base de cálculo na entidade, apontando os resultados ocorridos com sua implantação. Para a academia, o presente trabalho poderá servir como fonte de pesquisa para futuras consultas quando interessados em analisar este tema, contribuindo também para futuras pesquisas que tenham como objetivo o aperfeiçoamento da profissão.

\section{REFERENCIAL TEÓRICO}

\subsection{Cenário Econômico Brasileiro}

Segundo Ludwig, Borgert e Kremer (2015, p.1), O cenário atual da economia coloca o Brasil entre os países com inflação elevada e baixo crescimento, apresentando uma desaceleração dos indicadores econômicos. Para fortalecer a economia brasileira, o Governo Federal atual, instituiu o Plano Brasil Maior, adotando medidas importantes para sustentar o desenvolvimento econômico do país, dentre elas estão à desoneração da folha de pagamentos, sendo uma orientação geral da política econômica. Surgiu inicialmente pela Medida Provisória (MP) 540/2011, que foi convertida na Lei 12.546/2011. 
Tendo como objetivo a Lei ${ }^{\circ}$ 12.844/2013 contemplar os impactos de desoneração da folha de pagamento traz em decorrência ao cálculo da contribuição previdência, na qual as empresas que se enquadra nos artigos passaram a ter a contribuição sobre a receita de $1 \%$ ou 2\% sobre a folha de pagamento, a mudança será realizada apenas na parcela de contribuição patronal. Segundo Lahmet al.(2014), O objetivo da desoneração é de ampliar competitividade da indústria, estimular as exportações e, também, formalizar o mercado de trabalho. Acerca do favorecimento a desoneração da folha de pagamentos Juvella e Nascimento (2014) é favorável, afirma que,

\begin{abstract}
a desoneração da folha de pagamentos tem se tornado um tema bastante polêmico entre os empresários, administradores, autores de obras, e alguns governantes e entre todos os envolvidos no que tange essa nova mudança. Por se tratar de uma obrigatoriedade, há muitos que defendem que a desoneração deveria ser uma opção, pois em alguns casos beneficia apenas empresas que possuem uma demanda muito grande de mão de obra, e acaba por prejudicar aquelas que não têm uma demanda tão alta de empregados. (JUVELLA; NASCIMENTO, 2014).
\end{abstract}

A partir de $1^{\circ}$ de junho de 2015, as empresas sujeitas à desoneração da folha de pagamento, ou seja, as empresas que recolhem suas contribuições previdenciárias sobre a receita bruta (“CPRB”), passarão a contribuir com alíquotas (sobre a receita bruta) de 2,5\%, em substituição à alíquota de 1\% para as indústrias, e de 4,5\% para os demais segmentos, como, por exemplo, de informática, call Center e construção civil, em substituição à alíquota de $2 \%$.

Ainda assim, a desoneração pode ser benéfica para muitas empresas, dependendo da estrutura e organização de cada uma. O benefício acaba se concentrando na economia com a desoneração devida sobre a folha de pagamento do pessoal administrativo e sobre a folha do décimo terceiro. Kremer et al. (2015) complementam que,

O cenário de baixa competividade das empresas nacionais, o governo promoveu a desoneração da folha de pagamento em determinados setores a fim de reduzir os custos com previdência, impulsionar a economia e aumentar a formalização do mercado de trabalho. (KREMER et al; 2015).

Com a desoneração sendo opcional ficará por conta das empresas a decisão de utilizála ou não. A princípio a medida parece ser interessante, porém o aumento da alíquota da Contribuição Previdenciária sobre Receita Bruta (CPRB) para 4,5\% acaba por reduzir o benefício fiscal.

\title{
2.2 Encargos Sociais: Conceito e Influência Econômica
}


Nos últimos anos, tem crescido o debate sobre a questão dos encargos sociais no Brasil. O tema tem polarizado opiniões e constitui-se em importante divisor de águas quando se discutem alternativas de políticas de emprego e renda.

A carga tributária incidente sobre a atividade industrial no Brasil constitui-se em um significativo empecilho para o desenvolvimento econômico e social da gama empresarial do país. Algumas medidas urgentes devem ser tomadas para que o país atinja toda a efetividade de seu potencial. As medidas consistem em promover reformas estruturais, como a reforma política, a reforma da previdência e, talvez a mais premente, a reforma tributária. (BERTINI; WÜNSC, 2014).

Os encargos sociais incidentes sobre a folha restringem-se às contribuições sociais pagas pelas empresas como parte do custo total do trabalho, mas que não revertem em benefício direto e integral do trabalhador, segundo a DIEESE (Sistema de Informações para Acompanhamento das Negociações Coletivas no Brasil; 2006) as obrigações sociais recolhidas pelo governo sobre a folha de pagamentos (INSS, salário-educação, seguro de acidentes do trabalho, contribuições repassadas ao Sesi/Sesc, Senai/Senac, Incra e Sebrae), entram no cômputo dos encargos vários itens que compõem a remuneração do trabalhador, motivo pelo qual os "encargos" chegam a 125,90 \% ou até mais, como se verá adiante.

Para se chegar a umpercentual de $125,90 \%$ de encargos sociais, atribui a resumo dos encargos sociais sobre a Folha de Pagamento das empresas não optantes pelo Sim ples Nacional, no decorrer do mês, aos empregados, podendo ser observa-se no Quadro 2.

Quadro 2 - Composição dos encargos sociais para um índice de 125,90\%

\begin{tabular}{|c|c|c|c|}
\hline \multicolumn{2}{|c|}{ TABELA A } & \multirow{2}{*}{\multicolumn{2}{|c|}{ TABELA B }} \\
\hline INSS & $20 \%$ & & \\
\hline SENAC/SESC & $1,50 \%$ & $\begin{array}{l}\text { Repouso Semanal } \\
\text { Remunerado }\end{array}$ & $23,19 \%$ \\
\hline SENAI/SESI & $1 \%$ & $\begin{array}{c}\text { Férias }+ \\
1 / 3 \text { Constitucional }\end{array}$ & $12,67 \%$ \\
\hline SEBRAE & $0,60 \%$ & Feriados & $4,34 \%$ \\
\hline INCRA & $0,20 \%$ & Aviso Prévio Indenizado & $10,86 \%$ \\
\hline Salário-Educação & $2,50 \%$ & Auxílio Doença - 15 dias & $1,90 \%$ \\
\hline RAT & $2 \%$ & $13^{\circ}$ Salário & $10,86 \%$ \\
\hline FGTS & $8 \%$ & Licença-Paternidade & $0,02 \%$ \\
\hline Total & $35,80 \%$ & Total & $63,84 \%$ \\
\hline \multicolumn{4}{|c|}{ TABELA C } \\
\hline \multicolumn{3}{|c|}{ Multa rescisória de $40 \%$ do FGTS nas dispensas sem justa causa } & $2,10 \%$ \\
\hline \multicolumn{3}{|c|}{ Adicional $10 \%$ referente a Lei Complementar $n^{\circ} 110 / 01$} & $1,31 \%$ \\
\hline \multicolumn{3}{|c|}{ Total } & $3, \mathbf{4 1 \%}$ \\
\hline
\end{tabular}

Fonte: Dados da Pesquisa, baseado em Delphin (2015)

Nota: Resolução: $(0,3580 \times 0,6384)=(22,85 \%)+35,80 \%+63,84 \%+3,41 \%=$ Total dos Encargos $=125,90 \%$

Alguns dos encargos são fixados por lei como um percentual fixo sobre a folha de pagamentos. No entanto, a maioria tem que ser calculada a partir de estimativas que envolvem 
desde o número de dias efetivamente trabalhados até estatísticas sobre taxa de natalidade, acidentes no trabalho, número de conduções tomadas pelo trabalhador etc. Dessa forma, as estatísticas e estimativas aqui utilizadas refletem as especificidades do setor da construção residencial.

\subsection{Cálculo dos Encargos}

O recolhimento previdenciário das empresas em geral corresponde à aplicação das seguintes alíquotas, sobre o total das remunerações pagas ou creditadas, a qualquer título, no decorrer do mês, aos segurados empregados:

- $\mathbf{2 0} \%$ referente ao INSS Patronal para as empresas não optantes do Simples Nacional;

- 1\%, $2 \%$ ou 3\% referente ao Risco de Acidente do Trabalho (RAT) e Contribuição Adicional, se forem o caso, variando conforme o grau de risco, acrescido do fator acidentário de prevenção (FAP) a partir de janeiro de 2010;

- $\mathbf{5 , 8 0 \%}$ de contribuição variável de Outra Entidade (Terceiros), destinada às entidades SENAI, SESC, SESI, etc., onde o INSS se incumbe de arrecadar e repassar.

Assim incidirá sobre o valor mensal que foi reconhecido de salário, sendo em regra feral (varia de acordo com a atividade) um percentual totalizando entre $26,8 \%$ a $28,8 \%$, sobre o valor bruto da folha de pagamento.

\subsection{Lei 12.526/2011 e a Desoneração da Folha de Pagamento}

Integrando o Plano Brasil Maior (BRASIL, 2011b), lançado em agosto de 2011, o Governo Federal estabeleceu uma nova modalidade de desoneração da folha de pagamentos, incluída na Medida Provisória - MP n 540/2011, que se caracteriza pela substituição integral da contribuição patronal de $20 \%$ sobre a folha de pagamentos, por uma desoneração da folha de pagamentos.

Foram contempladas, inicialmente, empresas dos setores de tecnologia da informação, com alíquota substitutiva de 2,5\%, e do segmento têxtil e de calçados, com alíquota substitutiva de 1,5\%. A MP $\mathrm{n}^{\circ}$ 540/2011 foi convertida na Lei $\mathrm{n}^{\circ} 12.546 / 2011$, que ampliou o rol de empresas abrangidas pela desoneração. A Medida Provisória $n^{\circ} 651$ de 9 de julho de 2014 torna definitiva a desoneração da folha de pagamento para todos os setores relacionados no $\operatorname{art.} 7^{\circ}$ da Lei $n^{\circ} 12.546 / 11$, inclusive o setor da construção civil.

O CRC de São Paulo (CRCSP, 2014) afirma que: 


\begin{abstract}
A nova norma altera as alíquotas da contribuição previdenciária que incidem sobre a folha de salários, previstas na Lei $\mathrm{n}^{\circ}$ 12.546, de 14 de dezembro de 2011, e determina novos critérios para o cálculo da arrecadação, estabelecida pela Lei Orgânica da Seguridade Social, instituída pela Lei nº 8.212, de 24 de julho de 1991. As empresas beneficiadas deixam de recolher $20 \%$ da folha de pagamentos e passam a contribuir com um percentual que varia de $1 \%$ a $2 \%$ de sua receita bruta.
\end{abstract}

O Gráfico 1 ilustra a composição da contribuição previdenciária sobre perspectiva da tributação normal e sobre a desoneração da folha. Para fins de apresentação da metodologia, os cálculos foram divididos em 4 etapas, discriminadas a seguir: $\mathbf{1}^{\mathbf{a}}$ Etapa - Identificação dos Contribuintes Sujeitos à Desoneração da Folha (consiste na identificação do conjunto de contribuintes que, no mês de referência do cálculo, esteve sujeito à Desoneração da Folha). $\mathbf{2}^{\mathbf{a}}$ Etapa - Extração das Informações (utilização do número do Cadastro Nacional da Pessoa Jurídica - CNPJ dos contribuintes identificados na etapa anterior- Valor recolhido em DARF - Valor recolhido em GPS e - Valor da massa); $3^{\mathbf{a}}$ Etapa - Cálculo da Contribuição Previdenciária Teórica (a estimativa do quanto o contribuinte recolheria em GPS, a título de Contribuição Previdenciária Cota do Segurado (8, 9 ou 11\%), RAT (1 a 3\%) e a Cota Patronal sobre o total da folha (20\%)); $\mathbf{4}^{\text {a }}$ Etapa - Cálculo da Renúncia (resultante da substituição da Contribuição Previdenciária sobre a folha de pagamento pela CPRB, estão dispostas na Portaria Conjunta STN/RGB/INSS/MPS n² 2, de 28 de março de 2013).

Gráfico 1 - Composição da contribuição previdenciária sobre perspectiva da tributação normal e sobre a desoneração da folha

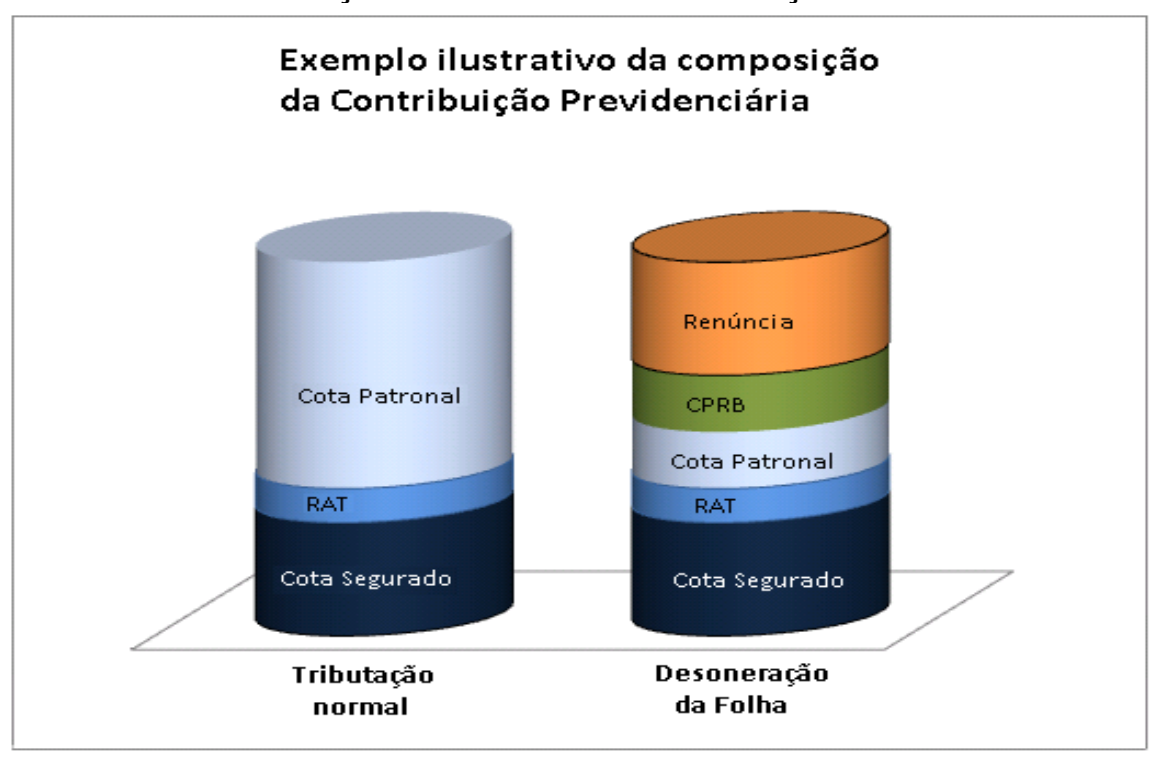

Fonte: Receita Federal (2015)

Observa-se no Gráfico 1, uma interligação da composição da tributação normal com a desoneração da folha onde consistirá forma de cálculo distinta, mas ambos possuem algum 
conjunto de contribuintes que a empresa realizou durante ao pagamento de contribuição previdenciária sobre a receita bruta (CPRB).

A partir do dia $1^{\circ}$ de dezembro de 2015, diante da publicação da Lei $n^{\circ} 13.161$ de 31 de agosto de 2015, entrarão em vigor as novas regras relativas à desoneração da folha de pagamentos. Salvo exceções pontuais, as alíquotas da contribuição patronal à Previdência Social passarão de $1 \%$ ou $2 \%$ sobre a receita bruta - conforme o setor - para $2,5 \%$ ou $4,5 \%$, respectivamente.

Tabela 1 - Mudança na alíquota da desoneração da folha de pagamento

\begin{tabular}{c|ccc}
\hline Setor & $\begin{array}{c}\text { Alíquota } \\
\text { Anterior }\end{array}$ & $\begin{array}{c}\text { Alíquota } \\
\text { Nova }\end{array}$ & $\begin{array}{c}\text { Aumento na } \\
\text { Alíquota }\end{array}$ \\
\hline Construção & $2 \%$ & $4,5 \%$ & $125 \%$ \\
\hline
\end{tabular}

Fonte: Receita Federal (2015)

Embora, a ideia inicial, acerca da desoneração é auxiliar na alavancagem das construtoras para a econômica Brasileia, tal benefício gera alguns conflitos internos no governo, que dificultaram o seu desenvolvimento, culminando assim, ocasionando aumento significante de $125 \%$ da alíquota da desoneração da folha de pagamento como fora demonstrado na Tabela 1 .

\section{METODOLOGIA}

\subsection{Métodos}

Com intuito de conceber informações mais detalhadas a pesquisa foi abordada um estudo qualitativo, no qual, buscando proporcionar uma análise fidedigna da Empresa. Segundo Liebscher (1998), a abordagem qualitativa é viável quando o fenômeno em estudo é complexo, de natureza social e de difícil quantificação. De acordo com o autor, para usar adequadamente a abordagem qualitativa, o pesquisador precisa aprender a observar, analisar e registrar as interações entre as pessoas e entre as pessoas e o sistema.

A pesquisa necessitou de bases estruturais que orientem seu desenvolvimento, sendo necessário a definição de métodos e procedimentos. Portanto, esse estudo classificou-se como uma pesquisa descritiva, tendo em vista que o objetivo geral desta pesquisa consistiu em analisar e evidenciar os reflexos da desoneração da folha de pagamento nas com atribuições previdenciárias. De acordo com Gil (2008),

As pesquisas descritivas possuem como objetivo a descrição das características de uma população, fenômeno ou de um a experiência. Por exemplo, quais as características de um determinado grupo em relação a sexo, faixa etária, renda familiar, nível de escolaridade etc. 
Acerca da amostra, mediante ao período da pesquisa verificou a variação de quantidade de funcionários desde o início da obrigatoriedade da desoneração da folha de pagamento, onde pode ser observado no Quadro 1, uma atenuação da quantidade do número de contratações formais na empresa Beta.

Quadro 1 - Quantidade do número de contratações formais na empresa Beta

\begin{tabular}{|c|c|}
\hline Mês & Contratações \\
\hline Janeiro/2015 & 7 \\
\hline Fevereiro/2015 & 7 \\
\hline Março/2015 & 7 \\
\hline Abril/2015 & 7 \\
\hline Maio/2015 & 7 \\
\hline Junho/2015 & 1 \\
\hline Julho/2015 & 6 \\
\hline
\end{tabular}

Fonte: Dados da Pesquisa (2016)

Todavia, uma das explicações para a redução no número de funcionários, podendo estar relacionado ao fato de que nos últimos anos o país vem se deparando numa crise econômica, e, as demissões, paulatinamente, superaram as contratações no período em que a empresa se encontrava desonerada.

\subsection{Unidade de Caso e Coleta de Dados}

A Beta LTDA EPP é um(a) Sociedade Empresaria Limitada de Mamanguape - PB fundada em 18/09/2012. Sua atividade principal é Construção de Edifícios. Vale ressaltar que, cujo nome da mesma, não será divulgada por não ter sido autorizada por seus administrados.

A coleta dos dados ocorreu no período de Janeiro a Julho de 2015, em uma empresa do ramo da construção civil. Na indústria mediante solicitação de informações por análise de documentos, quanto à organização, faturamento e contribuição previdenciária, sendo estas respondidas pelos contadores responsáveis. Desta forma, a análise das fontes de informações caracterizou-se como documental.

Ressaltando que os dados coletados se deram por meio da contabilidade desta empresa, que forneceu os dados correspondentes ao faturamento mensal, folha de pagamentos mensal, contribuição previdenciária paga antes da desoneração e informações quanto ao objeto social da empresa e dados da matrícula CNAE em que a referida empresa se enquadra. A análise dos dados foi realizada através de planilhas eletrônicas que permitiram a identificação da frequência das respostas e também a relação entre elas, para que pudessem ser construídas as tabelas. 


\section{ANÁLISE DOS RESULTADOS}

\subsection{Composição da Folha de Pagamento}

Apresentam-se na Tabela 2 os elementos que compuseram o total do salário de contribuição dos meses janeiro a dezembro de 2015, os quais serviram de base para apuração dos encargos previdenciários.

Tabela 2 - Resumo da composição da folha de pagamento

\begin{tabular}{|c|c|c|c|c|}
\hline & & & & \\
\hline \multirow{5}{*}{ pesquisa } & Janeiro/2015 & 7 & 3.873 .53 & \multirow{4}{*}{$\begin{array}{l}\text { Fonte: Dados da } \\
\text { (2016) }\end{array}$} \\
\hline & Fevereiro/2015 & 7 & $3.940,76$ & \\
\hline & Março/2015 & 7 & $2.816,62$ & \\
\hline & Abril/2015 & 7 & $4.027,49$ & \\
\hline & Maio/2015 & 7 & $4.080,00$ & \\
\hline Com a & Junho/2015 & 1 & 425,10 & finalidade \\
\hline & Julho/2015 & 6 & $3.364,15$ & \\
\hline
\end{tabular}

exigências do mercado, as pequenas e grandes empresas buscam a partir de medidas econômicas e financeiras uma forma de se sobressaírem perante os seus concorrentes. Todavia, com a crise econômica que assola atualmente o país, consequência de um mundo globalizado, estas alternativas não estão sendo prioritárias. O que se vê, são medidas drásticas em relação a demissões como visualizamos na tabela 4, onde as demissões superam as contratações no período que a empresa se encontrava desonerada.

\subsection{Comparativo da Contribuição da Empresa}

Para analisar se a desoneração da folha de pagamento foi vantajosa para a empresa "Beta", foi necessário comparar os dois meios de apuração, no qual, pela contribuição previdenciária sobre a folha de pagamentos que estava em vigor antes da desoneração, ou seja, considerando a contribuição de $20 \%$ sobre a folha de pagamentos (demonstrativo 1 Folha de Pagamento) e pelo faturamento da empresa com uma alíquota de 2\% (demonstrativo 2 - Receita Bruta) após a obrigatoriedade de aplicar a desoneração. Na tabela 3 demonstra em forma de comparativo, os dois critérios com base nos períodos de janeiro a julho de 2015 .

O valor do INSS, com o benefício da desoneração, corresponde à soma do RAT corresponde a $3 \%$ sobre o valor dos salários dos funcionários; INSS descontado sobre a folha de pagamento de cada funcionário que incide de $8 \%$ a $11 \%$ de acordo a base de cada empregado; e o valor da aplicação de $2 \%$ sobre o faturamento do mês.

Tabela 3 - Comparativo entre Folha de Pagamentos e Receita Bruta

$\begin{array}{lllllll}\text { jan/15 } & \text { fev/15 } & \text { mar/15 } & \text { abr/15 } & \text { mai/15 } & \text { jun/15 } & \text { jul/15 }\end{array}$




\begin{tabular}{c|ccccccc}
$\begin{array}{c}\text { Total de } \\
\text { Salário dos } \\
\text { Contribuintes } \\
\text { INSS }\end{array}$ & $11.063,28$ & $7.735,53$ & $8.842,13$ & $7.742,25$ & $7.799,33$ & $10.654,87$ & $10.706,81$ \\
$\begin{array}{c}\text { Descontado } \\
\text { folha dos } \\
\text { Funcionários } \\
\text { INSS }\end{array}$ & 995,70 & 618,84 & 707,37 & 619,38 & 623,95 & 852,39 & 856,54 \\
$\begin{array}{c}\text { Empresa } \\
\text { INSS }\end{array}$ & $2.212,66$ & $1.547,11$ & $1.768,43$ & $1.548,45$ & $1.559,87$ & $2.130,97$ & $2.141,36$ \\
$\begin{array}{c}\text { Contribuinte } \\
\text { RAT }\end{array}$ & 641,67 & 448,66 & 512,84 & 449,05 & 452,36 & 617,98 & 620,99 \\
$\begin{array}{c}\text { Total INSS s/ } \\
\text { Folha }\end{array}$ & 331,90 & 232,07 & 265,26 & 232,27 & 233,98 & 319,65 & 321,20 \\
$\begin{array}{c}\text { Faturamento } \\
\text { INSS RB }\end{array}$ & $122.181,92$ & $\mathbf{2 . 8 4 6 , 6 7}$ & $\mathbf{3 . 2 5 3 , 9 0}$ & $\mathbf{2 . 8 4 9 , 1 5}$ & $\mathbf{2 . 8 7 0 , 1 6}$ & $\mathbf{3 . 9 2 0 , 9 9}$ & $\mathbf{3 . 9 4 0 , 1 0}$ \\
$\begin{array}{c}\text { Total de INSS } \\
\mathbf{c} /\end{array}$ & 331,90 & 232,07 & 265,26 & 232,27 & 233,98 & 319,65 & 321,20 \\
$\begin{array}{c}\text { Desoneração } \\
\text { Diferença }\end{array}$ & $\mathbf{1 . 9 6 9 , 2 7}$ & $\mathbf{1 . 2 9 9 , 5 7}$ & $\mathbf{1 . 4 8 5 , 4 8}$ & $\mathbf{1 . 3 0 0 , 7 0}$ & $\mathbf{1 . 3 1 0 , 2 9}$ & $\mathbf{1 . 7 9 0 , 0 2}$ & $\mathbf{1 . 7 9 8 , 7 4}$ \\
$\begin{array}{c}\text { Percentual de } \\
\text { Economia } \\
\text { (\%) }\end{array}$ & $2.212,66$ & $1.547,11$ & $1.768,43$ & $1.548,45$ & $1.559,87$ & $2.130,97$ & $2.141,36$ \\
\hline
\end{tabular}

Fonte: Dados da pesquisa (2016)

Verifica-se que a empresa obteve vantagem com a desoneração da folha de pagamento, pois no período de janeiro a maio de 2015 recolheu INSS patronal sobre a receita bruta no valor de $\mathrm{R} \$ 5.890,00$. Comparando o período em que a empresa Beta esteve desonerada, verifica-se que houve uma diminuição no valor do imposto pago ao INSS.

De junho a julho de 2015 a empresa recolheu INSS patronal no valor de R \$ 1.790,02, mesmo somando os últimos nove meses desonerados, a contribuição foi menor que os sete meses em que a empresa não tinha entrado para a nova sistemática. Constatasse, que a empresa obteve vantagem com a desoneração da folha de pagamento, pois no período de janeiro a julho de 2015 a empresa Beta recolheu INSS Patronal sobre a receita bruta acima de $45 \%$, analisando os últimos meses, antes e após a empresa ter entrado para a nova sistemática pode-se ver claramente que após a desoneração a empresa apresentou diminuição do valor do imposto pago ao INSS. Tal efeito, pode ser verificado no Gráfico 2.

\section{Gráfico 2 - Base de Cálculo Folha de Pagamento X Faturamento}




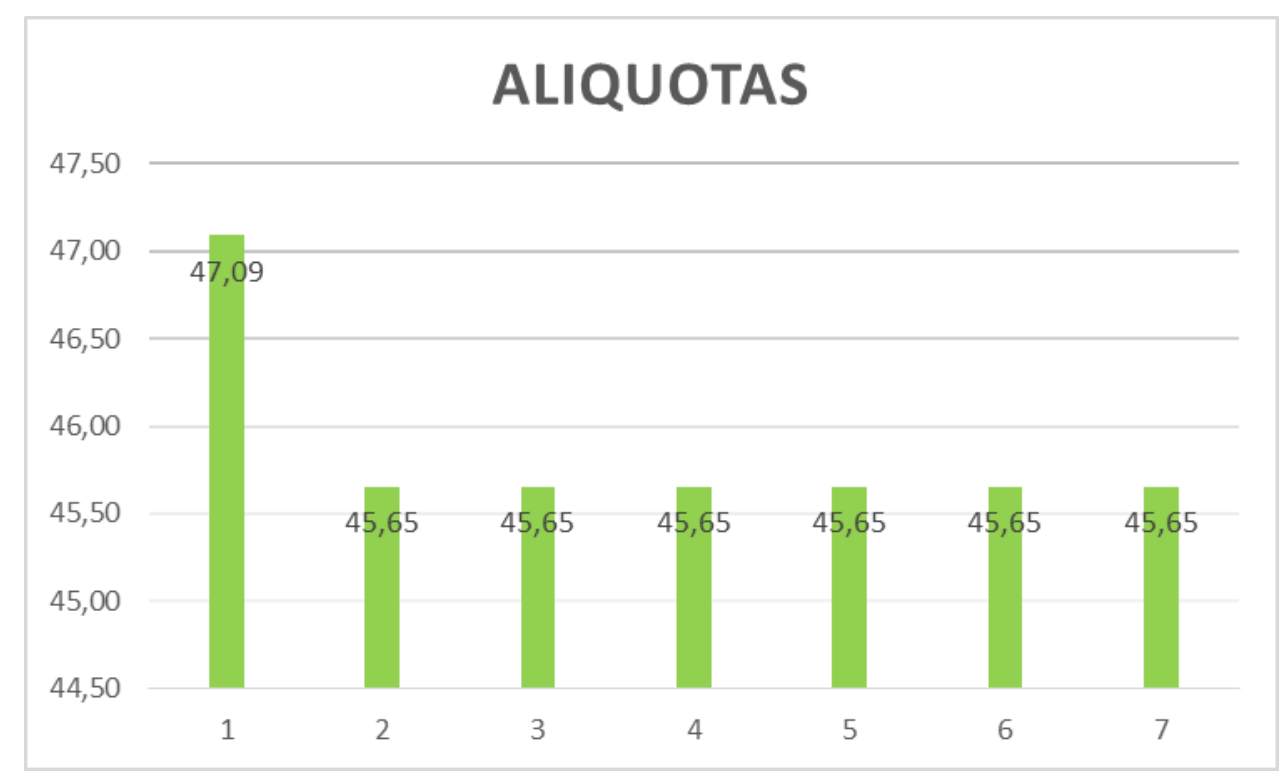

Fonte: Dados da pesquisa (2016)

Pode-se constatar pelo comparativo apresentado que houve uma redução do imposto pago pela empresa em todos os meses que serviram de base de estudo, o que indica uma grande vantagem para empresas do setor de construção civil, pois somando os sete meses base de estudo, a empresa obteve em média um total de redução que chegou a 45,65\%, valor bastante expressivo, como pode ser averiguado no Gráfico 2.

\section{CONCLUSÃO}

O presente estudo buscou, sob a perspectiva dos custos de uma empresa, verificar o impacto da desoneração da folha de pagamento em uma empresa de construção Civil, contemplada diretamente pela legislação, e em outra empresa de construção civil, que tem terceirizada a sua mão de obra, e, portanto, tem influência indireta da nova legislação.

Mediante as constantes alterações da legislação que instituiu a desoneração, utilizou-se como período base para análise o período em que a empresa Beta foi desonerada em 2015, na qual a alíquota para cálculo da contribuição previdenciária permaneceu inalterada, ocorrendo apenas à inclusão de novos ramos de atividade aos setores abrangidos.

Com base na análise dos dados concluiu-se que a empresa Beta teve um impacto financeiro relacionados aos benefícios que a mesma conseguiu com a desoneração da folha de pagamento, no qual, sua média de redução chegou a $45 \%$. Dessa forma, para a empresa em estudo, evidencia-se que houve vantagem ter realizado a opção para se enquadrar na nova sistemática de recolhimento patronal ao INSS, tendo em vista que o valor de INSS patronal que incide sobre a folha reduziu pela metade. 
O estudo concluiu também que alguns problemas conjunturais na economia podem estar corroborando para que as empresas encontrem algumas dificuldades para manterem-se competitivas no mercado. Em decorrência disso, as empresas tendem a diminuir suas operações e investimentos, refletindo diretamente no quadro de colaboradores, através do aumento das demissões em relação as constatações, o que pode ter fetado a empresa em estudo, tendo em vista a contrapartida solicitada pela medida não ter sido atendida.

Além dos dados apresentados no estudo, entende-se que existem outros que merecem ser pesquisados. Sendo assim, sugerem-se estudos futuros para avaliar as modificações ocorridas com a desoneração em outros segmentos, como por exemplo, no comércio, serviços de informática ou até mesmo da construção civil que também estão abrangidos pela desoneração da folha de pagamento.

\section{REFERÊNCIAS}

BERTINI, E; BORGERT. A; KREMER, A. O Impacto da Desoneração da Folha de Pagamentos no Comportamento dos Custos das Empresas de Construção Civil. In. VI CONGRESSO DE CONTABILIDADE. SANTA CATARINA: CBC, 2015.

BRASIL. Desoneração da Folha de Pagamentos - Perguntas e Respostas. 2012. Disponível em: Acesso em: 01/07/2015.

Lei $n^{0}$ 12.546, de 14 de dezembro de 2011. [2013b]. Disponível em:

<http://www.planalto.gov.br/ccivil_03/_ato2011-2014/2013/lei/l12844.htm>. Acesso em: 6 fevereiro de 2016.

CONSELHO REGIONAL DE CONTABILIDADE DE SÃO PAULO. Disponível em: http://crc-sp.jusbrasil.com.br/noticias/100064782/lei-n-12715-2012-desonera-folha-depagamento-de-empresas. Acesso em 3 de Novembro de 2015.

DIEESE (Sistema de Informações para Acompanhamento das Negociações Coletivas no Brasil.). Disponível em: http://www.dieese.org.br/. Acesso em 05 de Novembro de 2015.

DELPHIN. Encargos Sociais sobre a folha de pagamento. Disponível em: http://www.delphin.com.br/orientacao/66-encargos-sociais-sobre-a-folha-de-pagamento>. Acesso em: 29 de Maio de 2016.

ECHEVARRIETA, S. A desoneração da folha de pagamento. São Paulo, 2012.

GIL, Antônio Carlos. Como elaborar projetos de pesquisa. 5. ed. São Paulo: Atlas, 2008.

GOULART, A. Uma análise comparada do sistema tributário brasileiro. São Paulo. 2011, p.14. 
JUVELLA, S.; NASCIMENTO, E. Impactos da desoneração da folha de pagamentos no setor de construção civil. In: Anais do III SINGEP e II S2IS - São Paulo - SP - Brasil - 09, 10 e $11 / 11 / 2014$.

KERTZMAN, Ivan. A desoneração da folha de pagamento. São Paulo: LTr, 2012.

LIEBSCHER, P. Quantidade com qualidade? Ensinar métodos quantitativos e qualitativos em um programa LIS Mestre. Biblioteca Tendências, v. 46, n. 4, p. 668-680, 1998.

LUDWIG, M; WÜNSCH, P. O impacto financeiro e contábil da desoneração da folha de pagamento em indústrias calçadistas do Vale do Paranhana. Revista Eletrônico do curso de Contabilidade-FACCAT, 2015.

MELLO, L. C. B. B.; de AMORIM, S. R. L. O subsetor de edificações da construção civil no Brasil: uma análise comparativa em relação à união europeia e aos estados unidos. Produção, v. 19, n. 2, p. 388-399, 2009. 